\title{
Disrupting myddosome assembly in diffuse large B-cell lymphoma cells using the MYD88 dimerization inhibitor ST2825
}

\author{
XIN WANG ${ }^{1}$, YUAN TAN ${ }^{2}$, ZHENGLAN HUANG $^{2}$, NINGSHU HUANG $^{3}$, \\ MIAO GAO ${ }^{4}$, FANGZHU ZHOU ${ }^{5}$, JING HU ${ }^{2}$ and WENLI FENG ${ }^{2}$ \\ ${ }^{1}$ Department of Hematology, The First Affiliated Hospital of Chongqing Medical University; \\ ${ }^{2}$ Department of Clinical Hematology, Key Laboratory of Laboratory Medical Diagnostics Designated by \\ The Ministry of Education, Chongqing Medical University; ${ }^{3}$ Department of Clinical Laboratory, \\ Children's Hospital of Chongqing Medical University; ${ }^{4}$ Department of Clinical Laboratory, \\ The First Affiliated Hospital of Chongqing Medical University; ${ }^{5}$ Department of Clinical Laboratory, \\ Chongqing Traditional Chinese Medicine Hospital, Chongqing 400016, P.R. China
}

Received February 20, 2019; Accepted July 12, 2019

DOI: $10.3892 / o r .2019 .7282$

\begin{abstract}
Diffuse large B-cell lymphoma (DLBCL), the most common type of non-Hodgkin's lymphoma, is classified into germinal center and activated B cell (ABC) subtypes. The myeloid differentiation primary response gene 88 (MYD88) L265P mutation is the most prevalent oncogenic mutation among patients with ABC DLBCL, the subtype that has the more inferior outcome. MYD88 oligomerization driven by the L265P mutant augments myddosome assembly and triggers the activation of nuclear factor kappa-light-chain-enhancer of activated B cells (NF- $\mathrm{KB}$ ) signaling, highlighting MYD88 oligomerization as a potential therapeutic target for this malignancy. The synthetic peptidomimetic compound ST2825, which has previously been used as an anti-inflammatory agent, has been reported to inhibit MYD88 dimerization. In the present study, the anticancer effects of ST2825 were investigated using
\end{abstract}

Correspondence to: Dr Wenli Feng, Department of Clinical Hematology, Key Laboratory of Laboratory Medical Diagnostics Designated by The Ministry of Education, Chongqing Medical University, 1 Yixueyuan Road, Chongqing 400016, P.R. China E-mail: fengwl@cqmu.edu.cn

Abbreviations: DLBCL, diffuse large B-cell lymphoma; NHL, non-Hodgkin's lymphoma; GCB, germinal center B cell; $\mathrm{ABC}$, activated B cell; PFS, progression-free survival; BCR, B-cell receptor; TLR, toll-like receptors; CARD11, caspase recruitment domain-containing protein 11 ; NF- $\kappa \mathrm{B}$, nuclear factor-kappa $\mathrm{B}$; MYD88, myeloid differentiation primary response gene 88; IL-1R, interleukin-1 receptor; TIR, Toll/interleukin-1 receptor; DD, death domain; HMW, high-molecular-weight; WM, Waldenstrom macroglobulinemia; WT, wild-type; BTK, Bruton's tyrosine kinase; BCL-2, B-cell lymphoma-2; I $\mathrm{B}$, inhibitor of $\mathrm{NF}-\kappa \mathrm{B}$; CI, Combination index

Key words: myddosome, ST2825, MYD88, L265P, BTK, BCL-2, DLBCL
L265P-expressing ABC DLBCL cell lines. Using confocal microscopy and high-molecular-weight fraction experiments, it was revealed that L265P-associated myddosome assembly was disrupted by ST2825. The results also revealed that disrupting myddosome assembly promoted the death of ABC DLBCL cells harboring the L265P mutation, as well as downregulating survival signals, including the inhibition of NF- $\mathrm{KB}$ and the suppression of IL-10 and interferon- $\beta$ production. Further co-immunoprecipitation studies demonstrated that MYD88 bound to BTK in L265P-DLBCL cells, and that this binding was abrogated following ST2825 treatment. Furthermore, the combination of myddosome-assembly disruption and BTK or BCL-2 signaling inhibition led to synergistic ABC DLBCL cell death, and more robust inhibition of NF- $\mathrm{KB}$ activity or increased apoptosis, respectively. The results of the present study provide evidence that the synthetic peptidomimetic compound ST2825, which targets myddosome assembly, may serve as a pharmacological inhibitor. ST2825 has the potential for clinical use in patients with L265P DLBCL, and other B-cell neoplasms driven by activated MYD88 signaling.

\section{Introduction}

Diffuse large B-cell lymphoma (DLBCL) is an aggressive form of B-cell lymphoma, which is the most common type of non-Hodgkin's lymphoma (NHL), and comprises $\sim 30 \%$ of all NHL neoplasms. Over half of all DLBCLs are curable using standard chemotherapy (cyclophosphamide, doxorubicin, vincristine and prednisone) combined with rituximab (R-CHOP), while approximately one third of cases will relapse or become refractory following first line therapy $(1,2)$. The two primary subtypes of DLBCL, termed germinal center B cell (GCB) and activated $B$ cell $(\mathrm{ABC})$ have been identified via gene expression profiling studies (3). The distinct genetic characteristics of these two subtypes suggest that they arise from different stages of lymphoid differentiation, with the GCB subtype deriving from the lymphoid cells residing in the germinal center, and the $\mathrm{ABC}$ subtype from $\mathrm{B}$ cells at a plasmablastic stage. This results 
in different clinical features and prognoses, where following $\mathrm{R}-\mathrm{CHOP}$ combination treatment, the prognosis of patients with the ABC subtype is poorer than those with the GCB subtype, who possess a 3-year progression-free survival (PFS) rate of 40 vs. $75 \%$, respectively (4). The pathogenic hallmark of ABC DLBCL is the constitutive activation of the NF- $\kappa B$ pathway, which is often caused by mutations occurring following the upstream activation of the B-cell receptor (BCR) and Toll-like receptors (TLR) pathways (5). These activating mutations were identified in subsets of patients with ABC DLBCL, and include mutations in CD79B, caspase recruitment domain-containing protein 11 (CARD11) in the BCR pathway $(6,7)$ and myeloid differentiation primary response gene 88 (MYD88) in the TLR pathway (8).

The human TLRs, first reported in the 1990's, are functionally involved in both innate immunity and the initiation of adaptive immune responses (9). MYD88 is a key adaptor molecule for the majority of TLR and IL-1 receptor (IL-1R) signaling cascades. The MYD88 protein contains both a Toll/interleukin-1 receptor (TIR) domain that can bind to the TIR domain of TLRs, and a death domain (DD), which provides a docking site for IL-1R-associated kinases (IRAKs). It has been demonstrated that six MYD88 molecules, four IRAK4 and four IRAK1 or IRAK2 molecules are able to associate via their DDs to form a high-molecular-weight (HMW) (>180 kDa) complex, the myddosome. The myddosome platform is essential for the activation of the nuclear factor kappa-light-chain-enhancer of activated $\mathrm{B}$ cells $(\mathrm{NF}-\kappa \mathrm{B})$ pathway via a cascade of phosphorylation events that originate from the phosphorylation of IRAK4, the most upstream kinase in this cascade $(10,11)$. Highly recurrent somatic mutations in MYD88 were first demonstrated in ABC DLBCL by Ngo et al (8), with a specific point mutation (L265P) occurring most frequently; L265P was observed in $\sim 29 \%$ of ABC DLBCL cases, but rarely in GCB DLBCL. The high prevalence of MYD88 L265P in patients with Waldenstrom macroglobulinemia (WM) has also been reported in previous publications, with an observed mutation frequency rate of $87 \%$ (observed in 1,324 of 1,520 patients with WM, from 25 publications) (12). In addition, MYD88 L265P has also been identified in other types of B-cell neoplasm, with mutation frequency rates in monoclonal gammopathy of undetermined significance of the IgM class (IgM MGUS; 52\%), primary DLBCL of the central nervous system (CNS; 70\%), cutaneous DLBCL of leg-type (54\%) and testicular DLBCL (74\%) (12). Consistent with previous studies, the majority of these subtypes of DLBCL are of $\mathrm{ABC}$ origin. Ngo et al (8) further demonstrated that MYD88 L265P was a gain-of-function driver mutation, which promoted ABC DLBCL cell survival by assembling a myddosome complex and the phosphorylation of IRAK kinases; this resulted in constitutive $\mathrm{NF}-\kappa \mathrm{B}$ activation, type I interferon (IFN) signaling and IL-6/IL-10-engaged autocrine activation of the JAK-STAT 3 pathway (8).

In ABC DLBCL cells, interactions between MYD88 L265P-mutated and wild-type (WT) TIR domains enhance MyD88 oligomerization, which serves a key role in myddosome complex formation, resulting in the recruitment of IRAKs and induced NF- $\kappa$ B signaling activation (13). ST2825, a synthetic peptidomimetic compound, interferes with the association between MYD88 proteins, potentially by targeting the interface between the TIR domains (14). Although MYD88 L265P is essential in promoting the survival of ABC DLBCL cells, the therapeutic strategies for targeting MYD88 remain largely undetermined. In the present study, the ability of ST2825 to disrupt MYD88 oligomerization-induced myddosome assembly was investigated in ABC DLBCL cells, in addition to the subsequent ability to inhibit NF- $\mathrm{B}$ signaling and tumor cell survival.

\section{Materials and methods}

Reagents. ST2825 was purchased from MedChemExpress. The Bruton's tyrosine kinase (BTK) inhibitor ibrutinib, and B-cell lymphoma-2 (BCL-2) inhibitor ABT-199 were purchased from Selleck Chemicals. All drugs were dissolved in $100 \%$ dimethyl sulfoxide (DMSO). For all samples in all of the experiments, the final DMSO concentrations were diluted to $0.1 \%$ with cell culture media, including the vehicle controls.

Cell lines and cell culture. SU-DHL-4, OCI-LY10 and TMD8 cell lines were purchased from the Cell Bank of Type Culture Collection of the Chinese Academy of Sciences. The MYD88 L265P mutation of each cell line was identified using Sanger sequencing. The cells were cultured in RPMI-1640 supplemented with $10 \%$ fetal bovine serum (FBS; Gibco; Thermo Fisher Scientific, Inc.). The HEK293T cell line was cultured in Dulbecco's modified Eagle's medium (DMEM; Gibco; Thermo Fisher Scientific, Inc.) with $10 \%$ FBS. All cell lines were cultured at $37^{\circ} \mathrm{C}$ in a $5 \% \mathrm{CO}_{2}$ incubator.

Evaluation of cell viability and apoptosis. Cell viability was assessed using WST-1 reagent (Roche Diagnostics) as instructed by the manufacturer. Briefly, $2 \times 10^{4}$ cells/well were seeded into 96-well plates and treated with either the vehicle (DMSO) or ST2825 at serial concentrations for 24,48 or $72 \mathrm{~h}$. After treatment, $10 \mu \mathrm{l}$ WST-1 reagent was added to each well, followed by a 4 -h incubation at $37^{\circ} \mathrm{C}$. Cell viability was calculated by measuring the absorbance at $440 \mathrm{~nm}$ using a 96 -well plate reader, and the data were normalized to that of the vehicle-treated cells. For drug combination experiments, cell viability was determined $72 \mathrm{~h}$ after treatment with the indicated drugs. Flow cytometric analysis of apoptosis was performed using an Annexin V-FITC Apoptosis Detection kit (Sigma-Aldrich; Merck KGaA) 48 h after ST2825 treatment ( 5 or $10 \mu \mathrm{M}$ ) according to the manufacturer's protocol; the results were acquired using a flow cytometer (BD Influx; BD Biosciences) and analyzed using BD FACSuite software version 1.0.6. For drug combination experiments, the apoptotic cell populations were analyzed $48 \mathrm{~h}$ after treatment with the indicated drugs. The nuclear morphology of the apoptotic cells was further examined using DAPI staining. Cells were collected and coated onto slides after washing with PBS three times. The cells were then fixed in $4 \%$ paraformaldehyde at room temperature for $15 \mathrm{~min}$ and then permeabilized with $0.1 \%$ Triton $\mathrm{X}-100$ at $37^{\circ} \mathrm{C}$ for $5 \mathrm{~min}$. The cells were subsequently stained with $5 \mu \mathrm{g} / \mathrm{ml}$ DAPI in a dark room at $37^{\circ} \mathrm{C}$ for $15 \mathrm{~min}$. After three washes with PBS, the cells were visualized using a fluorescence microscope (Eclipse 80i; Nikon Corporation) under a 40x oil immersion objective.

Western blot analysis. Western blot analysis was performed as previously described (15). Cells were lysed with RIPA lysis buffer supplemented with proteinase and phosphatase inhibitors (Cell 
Signaling Technology, Inc.) at $4^{\circ} \mathrm{C}$ for $20 \mathrm{~min}$. The supernatants were collected after centrifugation at $13,000 \mathrm{x}$ g for $15 \mathrm{~min}\left(4^{\circ} \mathrm{C}\right)$, and the protein concentration was determined using a bicinchoninic acid (BCA) protein assay kit (Thermo Fisher Scientific, Inc.). Equal amounts of protein extract (30 $\mu \mathrm{g}$ per lane) were loaded for separation onto a 10\% SDS-PAGE gel and transferred to PVDF membranes (EMD Millipore), before blocking in 5\% non-fat milk/TBST at room temperature for $1 \mathrm{~h}$. Then, the membranes were incubated overnight at $4^{\circ} \mathrm{C}$ with primary antibodies (all purchased from Cell Signaling Technology, Inc., and used at a dilution of 1:1,000) against MYD88 (cat. no. 4823S), BTK (cat. no. 8547S), phospho-BTK (cat. no. 5082S), inhibitor of

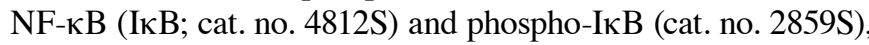
followed by incubation with anti-rabbit horseradish peroxidase (HRP)-conjugated secondary antibody (cat. no. sc-2030; Santa Cruz Biotechnology, Inc.; 1:5,000) for $1 \mathrm{~h}$ at room temperature. The $\beta$-actin antibody (cat. no. ab8227; Abcam) was used at a 1:1,000 dilution. Detection was performed using an enhanced chemiluminescence substrate (ECL; EMD Millipore), and the signals were visualized and analyzed using the Bio-Rad Gel Imaging System and the Cool Imager ${ }^{\mathrm{TM}}$ workstation II (Viagene, Biotech, Inc.).

MyD88 protein aggregation in DLBCL cell lines (OCI-LY10 and TMD8) was analyzed using fractionated cell lysates. Following overnight treatment with DMSO or $10 \mu \mathrm{M}$ ST2825, $5 \times 10^{6}$ cells were incubated in each well of a 6 -well plate and then collected and lysed using cell lysis buffer (Beyotime Institute of Biotechnology) supplemented with PMSF and Benzonase (Sigma-Aldrich; Merck KGaA). The protein concentration was determined using a BCA protein assay kit (Thermo Fisher Scientific, Inc.) and equal amounts of cell lysates $(60 \mu \mathrm{g})$ were then fractionated by centrifugation $(16,000 \mathrm{x} \mathrm{g}, 10 \mathrm{~min})$; the supernatant fractions were regarded as whole cell lysates (WCL) and the pellet fractions as insoluble HMW aggregates. The pellets were then washed with PBS and dissolved by boiling in SDS sample buffer with shaking. Western blotting was conducted using the aforementioned anti-MYD88 (Cell Signaling Technology, Inc.) and anti- $\beta$-actin (Abcam) antibodies and goat anti-rabbit HRP-conjugated secondary antibody at the indicated dilutions.

Co-immunoprecipitation. Cells from each line were lysed using cell lysis buffer for western and immunoprecipitation (Beyotime Institute of Biotechnology) supplemented with $1 \mathrm{mM}$ PMSF. The samples were centrifuged at $13,000 \mathrm{x} \mathrm{g}$ for $15 \mathrm{~min}$, and the protein concentration was determined using a BCA protein assay kit (Thermo Fisher Scientific, Inc.). Then protein A/G coated magnetic beads (Bio-Rad Laboratories, Inc.) were incubated with $5 \mu \mathrm{g}$ IP antibodies against MYD88 or BTK (Cell Signaling Technology, Inc.) at room temperature with rotation for $10 \mathrm{~min}$. After washing with PBS-T, the antibody-conjugated beads were added into the antigen-containing lysate, and rotated for $1 \mathrm{~h}$ at room temperature. Immunoprecipitates were then washed three times with PBS-T, separated on a magnetic stand and eluted using Laemmli loading buffer for further immunoblotting analysis.

Confocal microscopy. HEK293T cells were seeded into 12-well plates $\left(2 \times 10^{5}\right.$ cells/well) $24 \mathrm{~h}$ before transfection to achieve a confluency of $50-70 \%$. Cells were then transiently transfected with $2 \mu \mathrm{g}$ mCitrine-TIR WT or mCitrine-TIR L265P plasmids using Lipofectamine ${ }^{\mathrm{TM}} 2000$ (Invitrogen; Thermo Fisher Scientific, Inc.) according to the manufacturer's protocol. After $24 \mathrm{~h}$, the cells were treated with DMSO or $10 \mu \mathrm{M}$ ST2825 and incubated for a further $48 \mathrm{~h}$. Following incubation, the cells were observed using a laser scanning Nikon A1R confocal microscope under a 40x oil immersion objective (numerical aperture, 1.4). An excitation of 488 and 520-570 nm emission were used for visualization. The plasmids for mCitrine-TIR WT or L265P mutant were provided by Dr Roman Jerala (13).

$N F-\kappa B$ reporter assays. CMV-Renilla luciferase lentivirus (Cignal Lenti CMV Renilla Control; Qiagen, Inc.) was used as an internal control for normalization, and $\mathrm{NF}-\kappa \mathrm{B}$ reporter lentivirus with firefly luciferase expression (Cignal Lenti NF- $\kappa$ B Reporter; Qiagen, Inc.) was used as the experimental reporter. The two lentiviruses were used to co-transfect the OCI-LY10 and TMD8 cells. Briefly, OCI-LY10 and TMD8 cells were resuspended in $0.5 \mathrm{ml}$ lentivirus-containing medium (containing $250 \mu \mathrm{l}$ Cignal Lenti NF- $\kappa$ B Reporter and $250 \mu$ l Cignal Lenti CMV Renilla Control) at a concentration of $1 \times 10^{6}$ cells $/ \mathrm{ml}$ in a 24 -well tissue culture plate in the presence of polybrene $(8 \mu \mathrm{g} / \mathrm{ml})$. The plates were centrifuged at $800 \mathrm{x} \mathrm{g}$ for $90 \mathrm{~min}$ at $32^{\circ} \mathrm{C}$. The cells were then washed and resuspended in fresh medium for an additional $72 \mathrm{~h}$. Then puromycin and hygromycin were used together for selection. For the drug experiments, cells were subsequently seeded at a density of $4 \times 10^{5}$ cells $/ \mathrm{ml}$ and treated for $12 \mathrm{~h}$ with the vehicle, ST2825, ibrutinib or a combination of ST2825 and ibrutinib at the indicated concentrations. Luciferase activity was measured in 96-well plates using the Dual-Luciferase Reporter Assay system (Promega Corporation) according to the manufacturer's protocol.

Cytokine measurement. The two ABC DLBCL cell lines were cultured in fresh media and treated for $24 \mathrm{~h}$ with 5 or $20 \mu \mathrm{M}$ ST2825 or DMSO. The concentrations of IL-10 and IFN- $\beta$ in the culture supernatants were measured by ELISA (cat. no. DY217B-05 and DY814-05, respectively; R\&D Systems, Inc.) according to the manufacturer's protocol. All experiments were performed in triplicate.

Synergism analysis. Synergism of the drug combinations (including ST2825 combined with ibrutinib or ABT-199) was evaluated using CalcuSyn software (Premier Biosoft International), which is based on the median-effect principle applied by Chou and Talalay (16). The combined effects and combination index (CI) for each dose combination were calculated and are presented as a heat map. Drug synergism, addition and antagonism were defined by CI values of $<1.0,1.0$ and $>1.0$, respectively.

Statistical analysis. Statistical analysis of the experimental data was performed using GraphPad Prism software version 6 (GraphPad Software, Inc.), and the data are presented as the mean \pm standard deviation, unless otherwise indicated. The unpaired t-test was used to assess the statistical significance of the differences between two groups, and one-way analysis of variance with Dunnett's or Tukey's test was used for those between multiple groups. $\mathrm{P}<0.05$ was considered to indicate a statistically significant difference. 


\section{Results}

MYD88 oligomerization augmented via the L265P-mutated TIR domain is blocked by ST2825. To determine whether oligomerization of the MyD88 TIR-L265P mutants could be blocked by ST2825, MyD88 TIR WT or mutant linked to the fluorescent protein mCitrine were expressed in HEK293T cells. Consistent with the results of a previous report (13), mCitrine-TIR mutants were strongly aggregated, whilst this was not the case for the WT mCitrine TIR. Furthermore, the aggregation of mCitrine-TIR mutants was markedly inhibited following treatment with ST2825 (Fig. 1A).

The HMW fraction was separated from the cellular lysates via centrifugation, and western blotting was used to determine the presence of MyD88 aggregates in the pelleted HMW fractions. MyD88 aggregation was detected in the HMW fraction in DLBCL cell lines with the L265P mutation (OCI-LY10 and TMD8). The changes in MyD88 aggregation following treatment with ST2825 were then investigated by comparing the ratios of endogenous MyD88 levels between pelleted HMW fractions and whole cell lysates. Fig. 1B and C illustrate a significantly lower pellet:lysate ratio in the ST2825-treated cells compared with the DMSO treated cells, thus indicating that the degree of MyD88 aggregation was significantly decreased following ST2825 treatment. A previous study indicated that the formation of MYD88-mutant-containing aggregates coincided with that of myddosome complexes (13). According to these data, it may be that augmented MyD88 oligomerization is blocked by ST2825 in ABC DLBCL cells, resulting in the disruption of myddosome assembly.

Disruption of myddosome assembly inhibits cell survival and promotes apoptosis in ABC DLBCL cells with the L265P mutation. WST-1 assays were used to evaluate the impact of ST2825-induced myddosome assembly disruption on tumor cell survival. As presented in Fig. 2, ST2825 exerted greater cytotoxicity on MYD88-mutated (OCI-LY10 and TMD8) vs. WT (SU-DHL-4) B-cells. Compared with the DMSO control groups, the cell viability of OCI-LY10 cells treated with ST2825 for $72 \mathrm{~h}$ was decreased in a concentration-dependent manner, with $\sim 50 \%$ inhibition at $5 \mu \mathrm{M} \mathrm{ST2825, \sim 60 \%}$ at $10 \mu \mathrm{M}$ and $\sim 70 \%$ at $20 \mu \mathrm{M}(\mathrm{P}<0.01$; Fig. $2 \mathrm{~A})$. Similar results were observed in TMD8 cells ( $\mathrm{P}<0.01$; Fig. $2 \mathrm{~B})$. However, the growth inhibition effects of ST2825 on SU-DHL-4 cells were only $\sim 20-25 \%$ at 10 or $20 \mu \mathrm{M}$ after $72 \mathrm{~h}$ of treatment, though these results were still significant. Flow cytometry revealed that the percentage of apoptotic cells (including early and late apoptotic cells) was significantly increased in OCI-LY10 and TMD8 cells $48 \mathrm{~h}$ after treatment with ST2825 (P<0.01; Figs. 2D and S1), while no significant difference was observed in SU-DHL-4 cells. Consistent with these results, the characteristic apoptotic morphological changes (condensed and fragmented nuclear) were observed by DAPI staining in OCI-LY10 and TMD8 cells treated with ST2825, while there were no obvious morphological changes in SU-DHL-4 cells (Fig. 2E).

Activated MYD88 signaling pathway driven by the L265P mutation is inhibited by ST2825. Since the disruption of myddosome assembly inhibited survival and induced apoptosis in MYD88-L265P DLBCL cells, the present study investigated the underlying molecular mechanism responsible for this effect. Gain-of-function driver mutation L265P engages the NF- $\kappa \mathrm{B}$ pathway by facilitating the phosphorylation and degradation of I $\kappa$ B proteins (8). Treatment of ABC DLBCL cell lines with ST2825 resulted in decreased ratios of phosho-/total I $\mathrm{B}$ in both OCI-LY10 and TMD8 cells (Fig. 3A). To further investigate $\mathrm{NF}-\kappa \mathrm{B}$ activity, $\mathrm{NF}-\kappa \mathrm{B}$ reporter assays were performed. ST2825 decreased transcription of the NF- $\mathrm{B}$-dependent luciferase reporter in OCI-LY10 and TMD8 cells (Fig. 3B). In addition to the NF- $\kappa \mathrm{B}$ pathway, JAK-STAT3 signaling was also demonstrated to contribute to cell survival in ABC DLBCL. MYD88 L265P mutations promote JAK-STAT3 signaling via the increased production of IL-6 and IL-10 in ABC DLBCL tumors. Furthermore, the activation of MYD88 signaling in MYD88-L265P DLBCL cells can induce IFN- $\beta$ production, which may be involved in the immune modulation of the ABC DLBCL cell microenvironment (8). The present study demonstrated that treatment with ST2825 significantly reduced the secretion of IL-10 and IFN- $\beta$ (Fig. 3C and D), while such inhibition was not observed for IL-6 secretion (data not shown).

BTK is associated with MYD88, which is altered following treatment with ST2825 in MYD88 L265P-expressing ABC DLBCL cells. Chronically active BCR signaling, responsible for the constitutive activation of the $\mathrm{NF}-\kappa \mathrm{B}$ pathway, is important for cell survival in ABC DLBCL. The BCR signaling component BTK serves a key role in triggering $\mathrm{NF}-\kappa \mathrm{B}$ activation in the majority of ABC DLBCLs $(6,17)$. According to the sequencing results of 155 ABC DLBCL biopsy samples, Ngo et al (8) identified that the most common mutations were found in MYD88, CD79B/A, A20 and CARD11. These mutations partially overlapped, and the overlap between the MYD88 L265P and CD79B/A mutations had the highest frequency. Among cases with a MYD88 L265P mutation, 34\% had a simultaneous CD79B/A mutation, which was reversed among cases with a CD79B/A mutation; even more had a simultaneous MYD88 L265P mutation (43\%). These data indicate that there may be crosstalk between chronically-active BCR and MYD88 signaling (8). In a previous study, co-immunoprecipitation experiments revealed that in HEK293 cells, ectopically expressed BTK associated with MYD88 (18). In addition, it was also reported that BTK interacted with MYD88 in lipopolysaccharide-stimulated macrophages to promote the activation of MYD88-dependent pathways (19). In the present study, co-immunoprecipitation experiments where performed to investigate whether endogenous MYD88 interacts with BTK in ABC DLBCL cells, with activation of the MYD88 signaling pathway driven by the L265P mutation. Robust MYD88 co-immunoprecipitation with BTK was observed in L265P-expressing ABC DLBCL cells (OCI-LY10 and TMD8) (Fig. 4A). This binding between BTK and MYD88 was also confirmed through reverse pull-down studies (Fig. 4B). It was further demonstrated that the binding of BTK with MYD88 was inhibited following treatment with ST2825 in OCI-LY10 and TMD8 cells (Fig. 4C). In addition, treatment with ST2825 decreased the ratio of phos-/total BTK expression in OCI-LY10 and TMD8 ABC DLBCL cell lines (Fig. 3A).

Disruption of myddosome assembly synergizes with BTK inhibition to enhance ABC DLBCL cell death. MYD88 and $\mathrm{BCR}$ signaling often converge at $\mathrm{I} \kappa \mathrm{B}$, leading to constitutive 
A
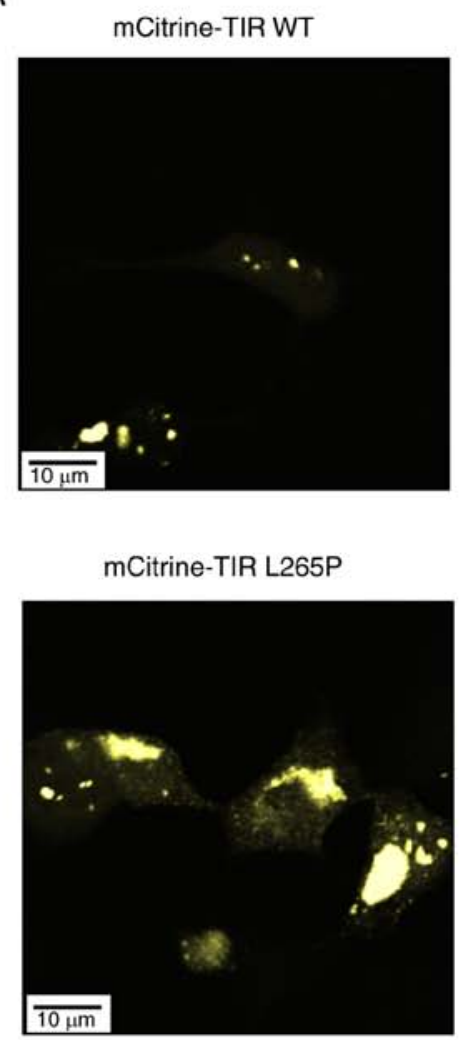

B

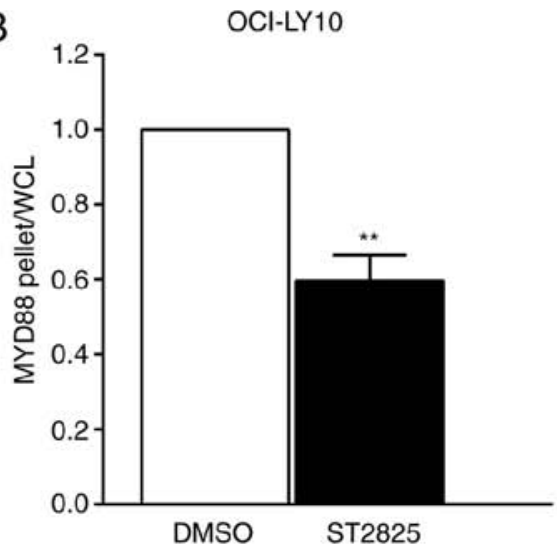

mCitrine-TIR WT +DMSO

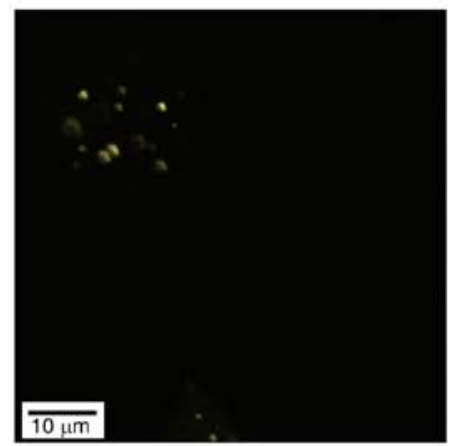

mCitrine-TIR L265P

+DMSO

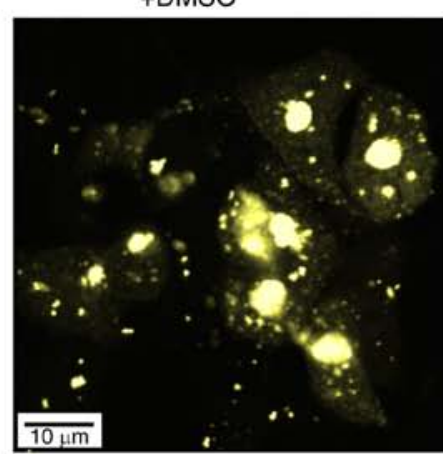

mCitrine-TIR WT +ST2825

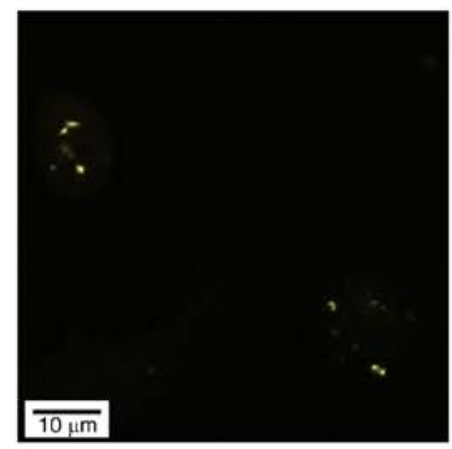

mCitrine-TIR L265P

+ST2825

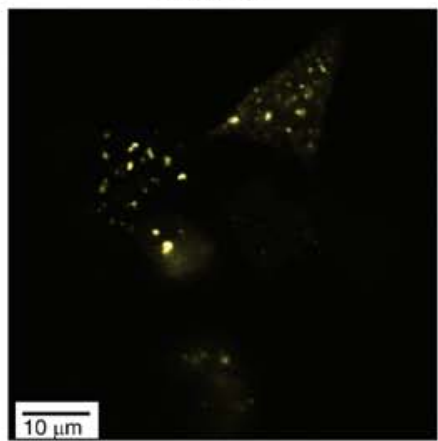

TMD8
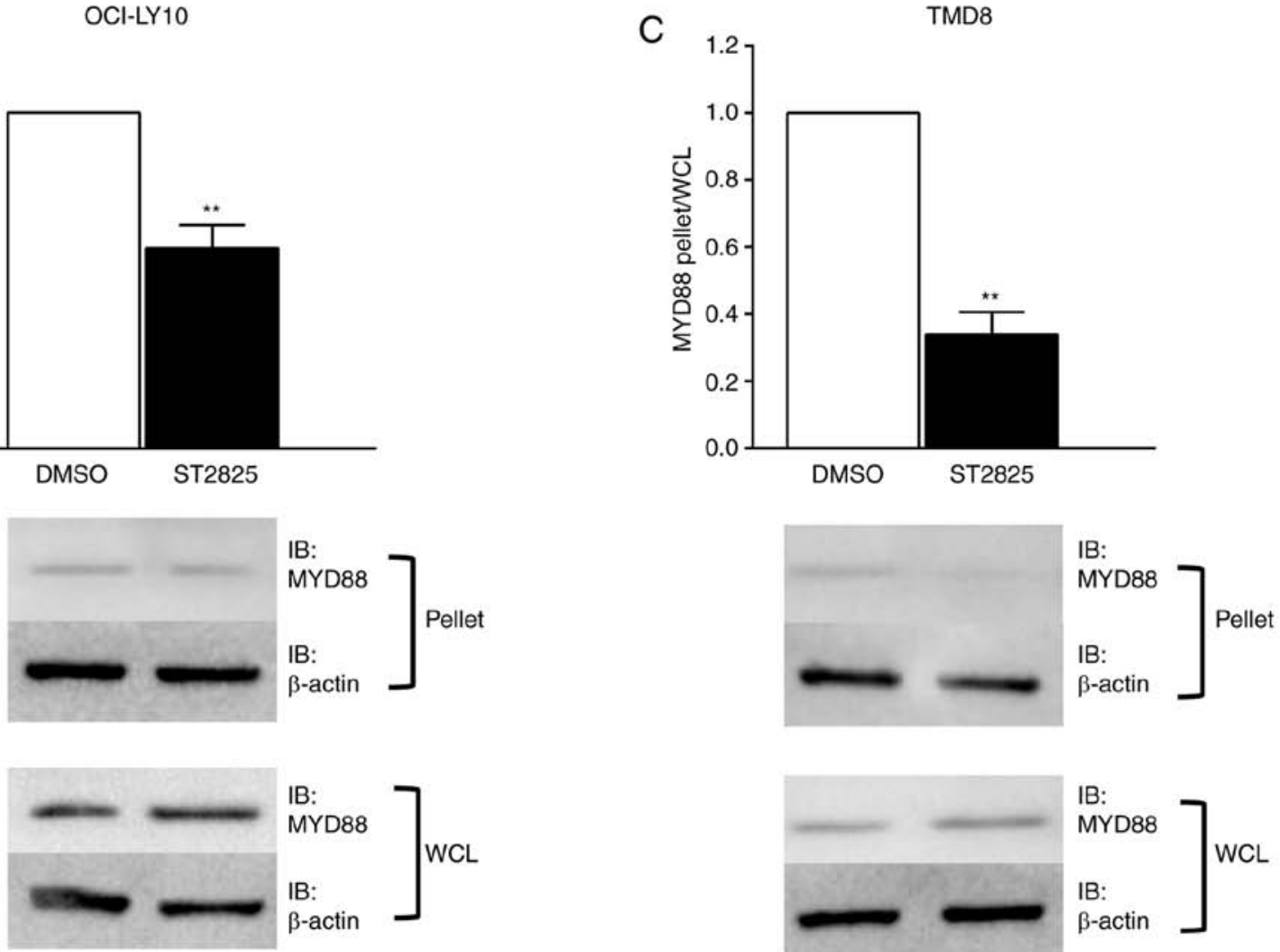

Figure 1. ST2825 inhibits MYD88 oligomerization in L265P-expressing cells. (A) HEK293T cells were transfected with WT mCitrine TIR or an mCitrine-TIR L265P mutant. After $24 \mathrm{~h}$ of transfection, the cells were incubated for a further $24 \mathrm{~h}$ with DMSO or $10 \mu \mathrm{M} \mathrm{ST2825}$. Following incubation, the cells were fixed and visualized under a confocal microscope at $x 400$ magnification. The representative images are provided from $\geq 3$ independent experiments. (B, C) The cell lysate and pellet fractions were separated by centrifugation and analyzed using SDS-PAGE followed by anti-MyD88 and anti- $\beta$-actin immunoblotting. Relative MYD88 and $\beta$-actin expression levels were quantified and plotted as the $\beta$-actin-normalized ratios of the MYD88 pellet vs. lysate. Comparison of the pellet vs. lysate ratio in (B) OCI-LY10 and (C) TMD8 cells following treatment with DMSO or ST2825. Data are representative of three independent experiments expressed as the mean \pm standard deviation, and a single representative immunoblot. ${ }^{* *} \mathrm{P}<0.01$. MYD88, myeloid differentiation primary response gene 88 ; TIR, Toll/interleukin-1 receptor; WT, wild-type; WCL, whole cell lysate; IB, immunoblot. 


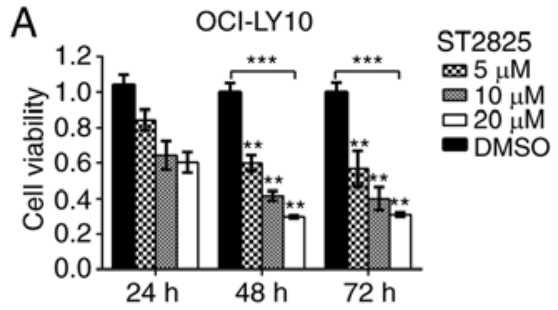

B

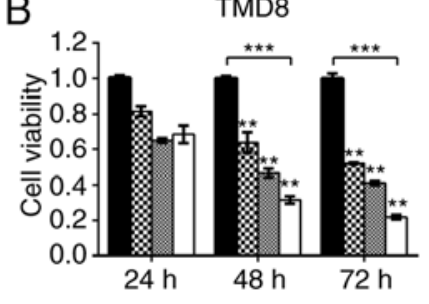

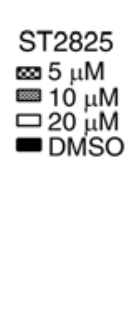

C
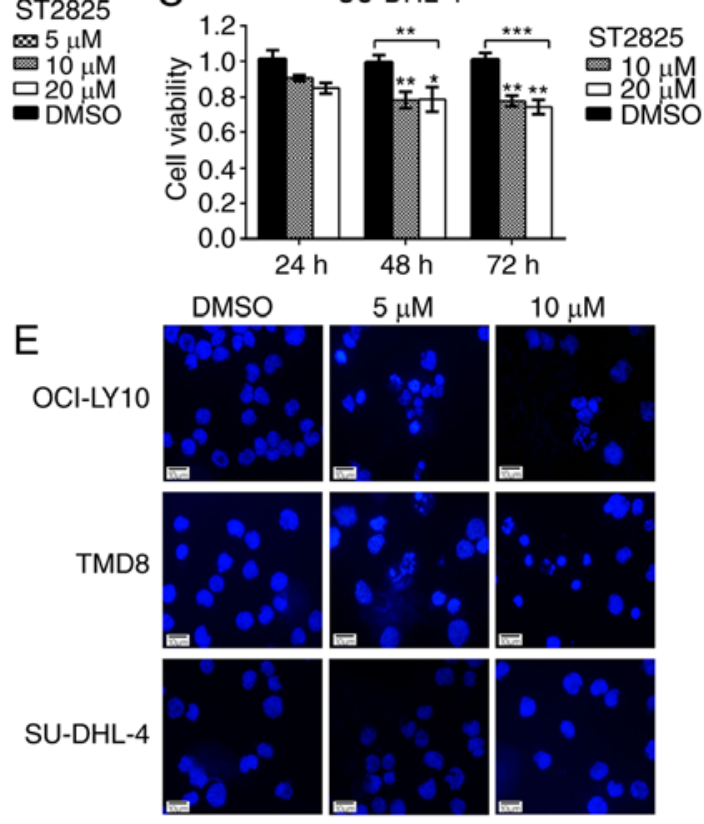

$\mathrm{E}$

OCI-LY10

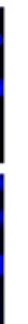

D $[\%]$

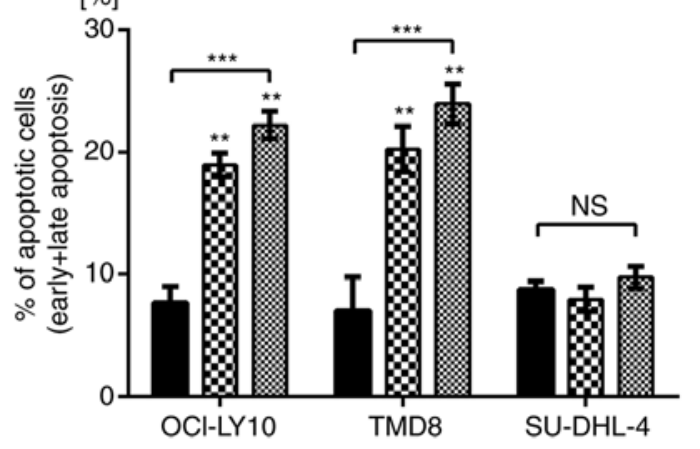

ST2825

Do $5 \mu \mathrm{M}$

ख $10 \mu \mathrm{M}$

DMSO

Figure 2. Inhibition of MYD88 oligomerization is associated with decreased survival and increased apoptosis in MYD88-dependent DLBCL cells. (A-C) Cell viability assay using DLBCL cells treated with ST2825 or DMSO. (D) Apoptosis in DLBCL cells treated with ST2825 or DMSO for 48 h was detected by flow cytometry following annexin V/propidium iodide staining. Statistical analysis was conducted using one-way ANOVA with Dunnett's post hoc test. (E) Morphological alterations of the apoptotic cells were detected via DAPI staining. Data are presented as the mean \pm standard deviation from experiments with three replicates. ${ }^{*} \mathrm{P}<0.05 ;{ }^{* *} \mathrm{P}<0.01 ;{ }^{* * *} \mathrm{P}<0.001$. MYD88, myeloid differentiation primary response gene 88 ; DLBCA, diffuse large B-cell lymphoma.

activation of the NF- $\kappa \mathrm{B}$ pathway in ABC DLBCL cells. In addition, a recent study demonstrated that MYD88, the BCR and TLR9 form a multi-protein supercomplex, which drives pro-survival-associated $\mathrm{NF}-\kappa \mathrm{B}$ signaling in ibrutinib-responsive DLBCL cells (20). Furthermore, the present study identified the direct interaction between BTK and MYD88 in ABC DLBCL cell lines. Thus, the potential dual inhibition of MYD88 and BTK signaling and its synergistic effects on ABC DLBCL cell death were investigated. The combination of ST2825 and the BTK inhibitor ibrutinib promoted OCI-LY10 and TMD8 cell death (Figs. 5A and B, S2A and B). The inhibitory effect for each combination at different doses was visualized using a heat map. Analysis of the CI indicated that ST2825 and ibrutinib were synergistic at most doses, though greater synergistic effects were observed at higher doses of ST2825 ( $\geq 1.3 \mu \mathrm{M})$ for both OCI-LY10 and TMD8 cells (Figs. 5C and S2C). The enhanced cytotoxicity was associated with stronger inhibition of $\mathrm{NF}-\kappa \mathrm{B}$ activity in tumor cells treated by dual inhibition, compared with that of each drug alone (Figs. 5D and S2D).

Disruption of myddosome assembly synergizes with BCL-2 inhibition to enhance $A B C D L B C L$ cell death. BCL-2 upregulation is prevalent in $\mathrm{B}$-cell lymphoma and promotes tumor cell survival by blocking apoptosis $(21,22)$. In addition, high BCL-2 expression levels were associated with poor clinical outcome in patients with ABC DLBCL (23). Given that BCL-2 serves a key role in the underlying oncogenic mechanism of B-cell lymphoma, BCL-2-targeted therapy has developed rapidly in recent years (24). In the present study, combination treatment with ST2825 and the BCL-2 inhibitor ABT-199 enhanced OCI-LY10 and TMD8 cell death (Figs. 6A and B, S3A and B). Analysis of the CI indicated that ST2825 and ibrutinib were synergistic at higher doses of ST2825 $(\geq 1.3 \mu \mathrm{M})$ and ABT-199 $(\geq 0.5 \mu \mathrm{M})$ in OCI-LY10 cells (Fig. 5C). Similar results were revealed in TMD8 cells (Fig. S3C). This combination treatment also consistently promoted apoptosis, as indicated by the increased number of apoptotic cells (including early and late apoptotic cells) detected by flow cytometry, compared with treatment with the individual drugs alone (Figs. 6D, S3D and S4).

\section{Discussion}

Recurrent MYD88 L265P mutations have been demonstrated in numerous types of B-cell neoplasm, including IgM MGUS, WM, DLBCL, mucosa-associated lymphoid tissue lymphoma and chronic lymphocytic leukemia (12). MYD88 L265P has been demonstrated to be the most frequently occurring mutation in the ABC subtype of DLBCL (20-40\%), whereas it is rarely observed in the GCB subtype $(8,17,25,26)$. A study in Spain reported that the MYD88 L265P mutation was significantly associated with inferior PFS and overall survival in patients with DLBCL $(\mathrm{P}<0.01)$, and was identified as a significant risk factor for mortality (hazard ratio, 2.4) via multivariate Cox regression analysis (27). More recently, two studies identified four or five subtypes of DLBCL based on distinct genetic features and pathogenetic mechanisms, via comprehensive genetic analyses. The results of both studies demonstrated that the subtype associated with more frequent mutations in MYD88 indicated a less favorable patient outcome $(25,26)$.

MYD88 L265P was identified as an oncogenic driver mutation, with enhanced phosphorylation of IRAK kinases and activation of the NF- $\mathrm{BB}$ and JAK-STAT3 signaling pathways, resulting in the promotion of cell survival in numerous $\mathrm{B}$-cell neoplasms, including ABC DLBCL $(8,12,28)$. Furthermore, mice 


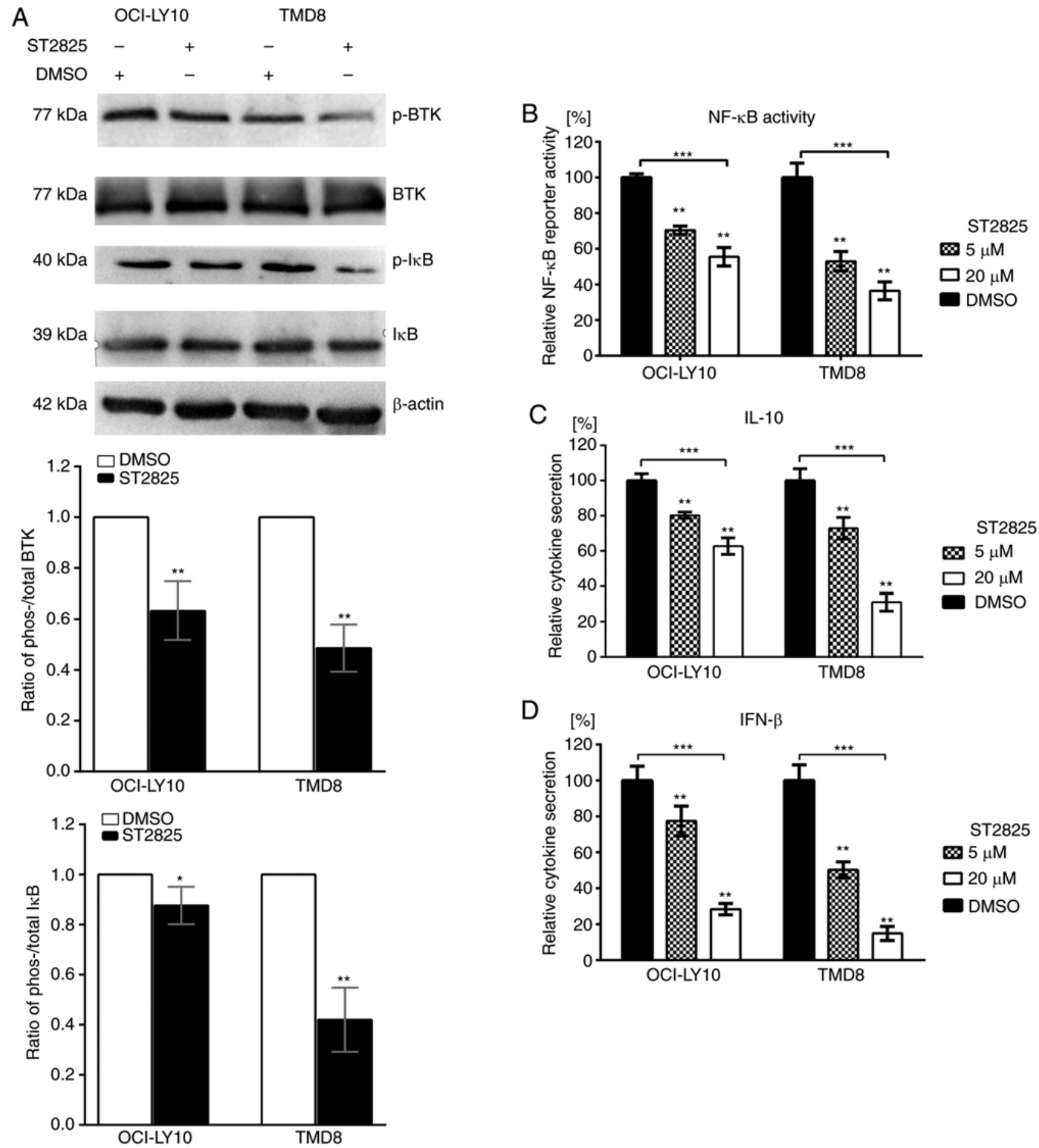

Figure 3. Effects of ST2825 on the MYD88 signaling pathway in ABC DLBCL cells with the MYD88 L265P mutation. (A) ABC DLBCL lines (OCI-LY10

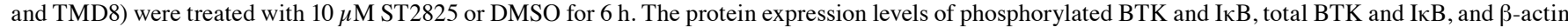
were determined via western blotting. Upper: Western blot results are representative of three independent experiments; lower: Both the phosphorylated and

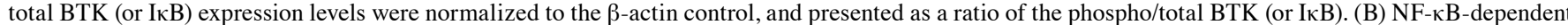
luciferase activity in ABC DLBCL lines treated with ST2825 or DMSO for $24 \mathrm{~h}$. Data are presented as the mean \pm standard error of the mean from three independent experiments. (C) Secretion of IL-10 from ABC DLBCL cells treated for $24 \mathrm{~h}$ with ST2825 or DMSO. (D) Secretion of IFN- $\beta$ from ABC DLBCL cells treated for $24 \mathrm{~h}$ with ST2825 or DMSO. Statistical analysis by one-way ANOVA with Dunnett's post hoc test. Data are presented as the mean \pm standard deviation from experiments with three replicates. ${ }^{*} \mathrm{P}<0.05 ;{ }^{* *} \mathrm{P}<0.01 ;{ }^{* * *} \mathrm{P}<0.001$. MYD88, myeloid differentiation primary response gene 88 ; DLBCA, diffuse large B-cell lymphoma; ABC, activated B cell; BTK, Bruton's tyrosine kinase; IkB, inhibitor of nuclear factor kappa B kinase; IFN, interferon; p-, phosphorylated.

occasionally developed ABC-DLBCL-like clonal lymphomas following conditional expression of MYD88 L265P in B cells specifically $(29,30)$. MYD88 is a central adaptor to the TLRs/ IL-1R signaling pathway, which contains three distinct domains: A C-terminal TIR domain, an N-terminal DD and a short linker region in-between (31). During normal immune responses, TLRs are primarily stimulated by foreign ligands such as the chemical components of infecting microbes. Following ligand binding, MYD88 is recruited to the activated receptor, resulting in heterodimerization with the receptor and homodimerization 
A

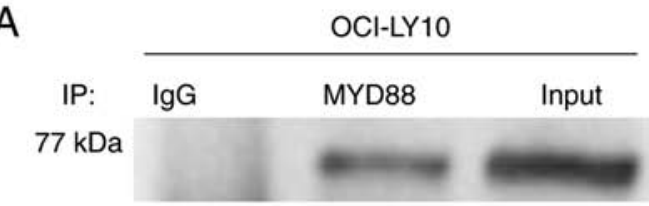

$33 \mathrm{kDa}$

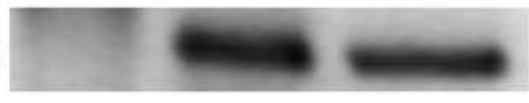

B

B

IP:

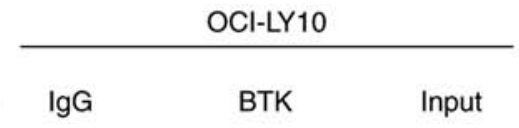

$33 \mathrm{kDa}$

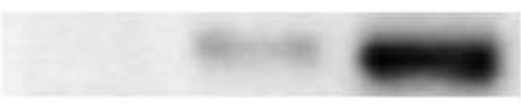

$$
77 \mathrm{kDa}
$$

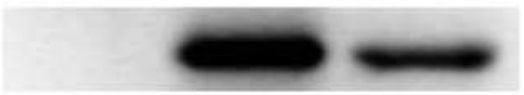

C
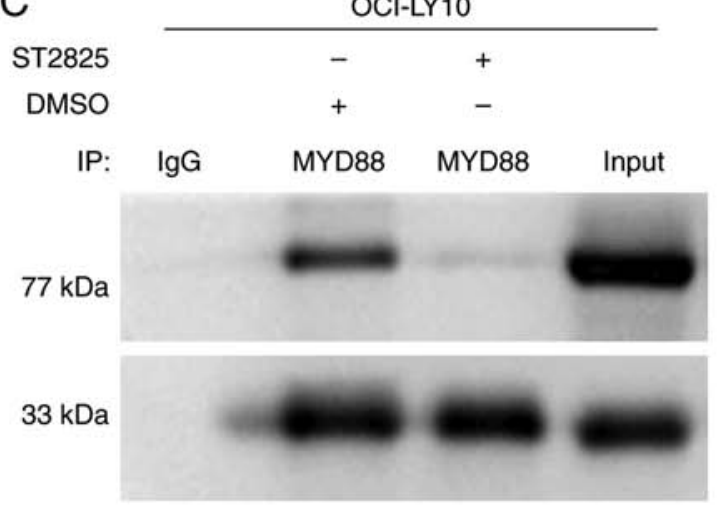
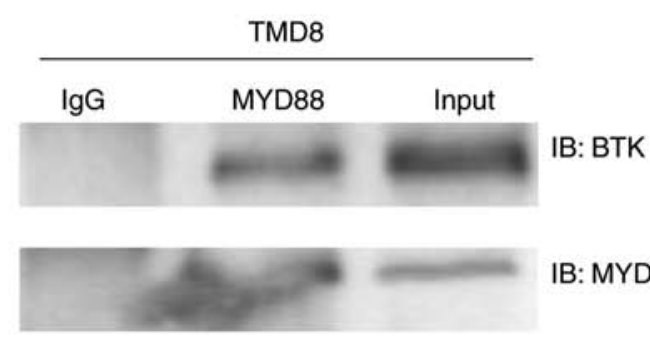

IB: MYD88
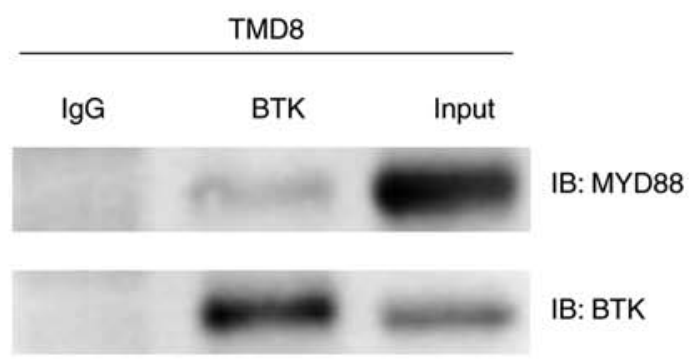

IB: BTK

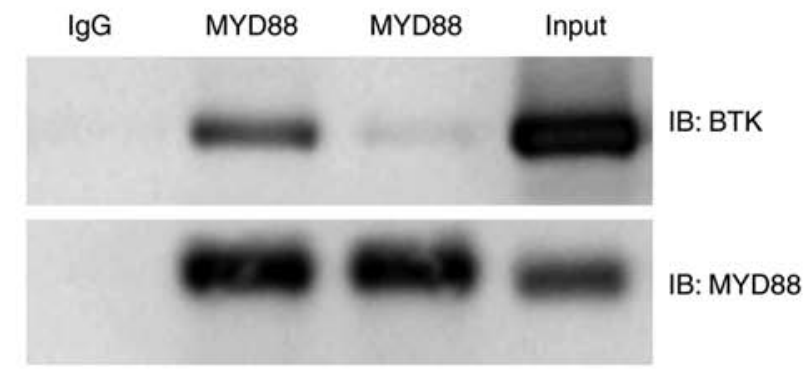

Figure 4. Association between BTK and MYD88 identified via co-immunoprecipitation, and altered following treatment with ST2825 in MYD88 L265P-expressing ABC DLBCL cells. (A) Immunoprecipitation of cell lysates was performed via pull-down with an anti-MYD88 antibody followed by IB with an anti-BTK antibody. (B) In a reciprocal experiment, pull-down was performed with and anti-BTK antibody and IB with anti-MYD88 antibodies. (C) Immunoprecipitation of BTK with MYD88 was conducted following a 6-h treatment with $20 \mu \mathrm{M}$ ST2825 or DMSO in MYD88 L265P mutant-ABC DLBCL cells (OCY-LY10 and TMD8). The data present a representative of at least two independent experiments. MYD88, myeloid differentiation primary response gene 88; BTK, Bruton's tyrosine kinase; ABC, activated B cell; DLBCA, diffuse large B-cell lymphoma; IB, immunoblot; IP, Immunoprecipitation; IgG, immunoglobulin G.

with another MyD88 molecule via TIR-TIR interactions $(32,33)$. These MYD88 oligomers further recruit the IRAKs via DDs, promoting myddosome formation and triggering subsequent downstream NF- $\kappa$ B and JAK-STAT3 signaling. The MYD88 L265P mutation, located in the TIR domain, reinforces dimerization between the mutant and WT TIR domains and augments MYD88 oligomerization. In contrast to native MYD88 oligomers, those containing L265P mutants can trigger myddosome assembly and constitutive activation of $\mathrm{NF}-\kappa \mathrm{B}$ signaling in the absence of external stimuli (13,34). The disruptive power of the proline residue potentially contributes to augmented oligomerization of MYD88 mutant TIR domains. The leucine-to-proline substitution at position 265 in the $\beta$-sheets (at the hydrophobic core of MYD88) would disrupt the secondary structure of the TIR domain, thus stabilizing the core of the TIR domain dimer interface $(12,35)$. The BB-loop, interacting with the $\alpha$ E-helix, is critical for MYD88 TIR-TIR interactions $(35,36)$. ST2825, a synthetic peptidomimetic that interacts with the BB-loop, competently inhibits MYD88 WT TIR-TIR interactions (14). Furthermore, it was observed that ST2825 was able to disrupt the aggregation of MYD88 mutant TIR domains in the present study, thus resulting in decreased cell viability and increased apoptosis of MYD88 L265P-expressing ABC DLBCL cells.

The NF- $\kappa \mathrm{B}$ transcription factor family (which can be activated by the MYD88 L265P mutation) serves a crucial role in ABC DLBCL cell survival $(8,37)$. I $\kappa \mathrm{B} \alpha$ has been regarded as a critical component of the NF- $\kappa \mathrm{B}$ signaling pathway. The present study demonstrated that $\mathrm{I} \kappa \mathrm{B} \alpha$ phosphorylation was blocked by inhibiting MYD88 oligomerization in L265P-expressing ABC DLBCL cells treated with ST2825. Consistent with these results, decreased NF- $\kappa$ B activity was observed following ST2825 treatment using a luciferase $\mathrm{NF}-\kappa \mathrm{B}$ reporter assay. Furthermore, the present study also revealed that ST2825 decreased the secretion of IL-10 and IFN- $\beta$ (the production of which are mediated by MYD88), which may be involved in the immune modulation of the ABC DLBCL microenvironment (8).

$\mathrm{BTK}$, a mediator from BCR activity to $\mathrm{NF}-\kappa \mathrm{B}$, serves an essential role in chronically-active BCR signaling, which supports tumor cell survival in ABC DLBCL cells $(6,17)$. As reported by Yang et al (38), it was also observed that MYD88 
A

\begin{tabular}{|c|c|c|c|c|c|c|c|}
\hline & \multicolumn{7}{|c|}{ ST2825 ( $\mu \mathrm{M})$} \\
\hline \multirow{7}{*}{ 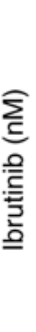 } & & 0 & 0.1 & 0.4 & 1.3 & 4 & 12 \\
\hline & 0 & 0 & 11.6 & 18.9 & 29.1 & 48.5 & 60.9 \\
\hline & 0.04 & 10.3 & 22.4 & 27 & 40.2 & 50.1 & 69.7 \\
\hline & 0.13 & 20.5 & 28.3 & 36.1 & 43.2 & 54.1 & 71.2 \\
\hline & 0.39 & 33.7 & 33.1 & 40.9 & 46.9 & 60.9 & 71.5 \\
\hline & 1.17 & 55.2 & 59 & 70.6 & 67.7 & 70.1 & 75.4 \\
\hline & 3.5 & 75.8 & 73.3 & 80.3 & 81.8 & 80.9 & 82.8 \\
\hline
\end{tabular}

C

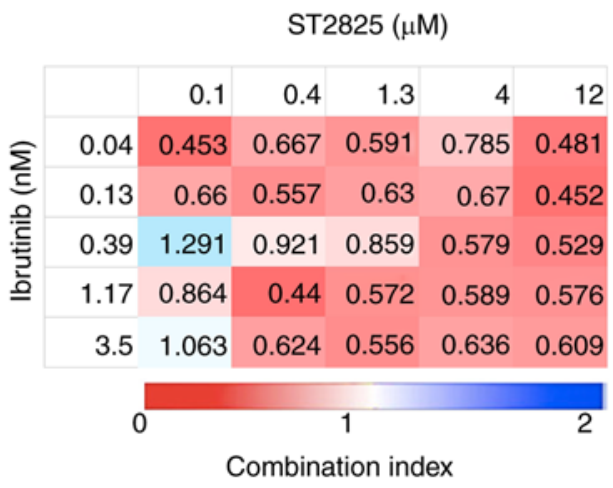

B

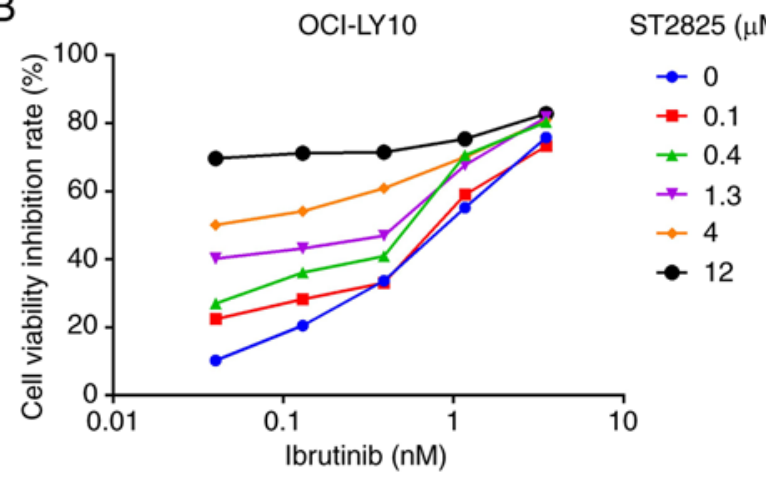

D

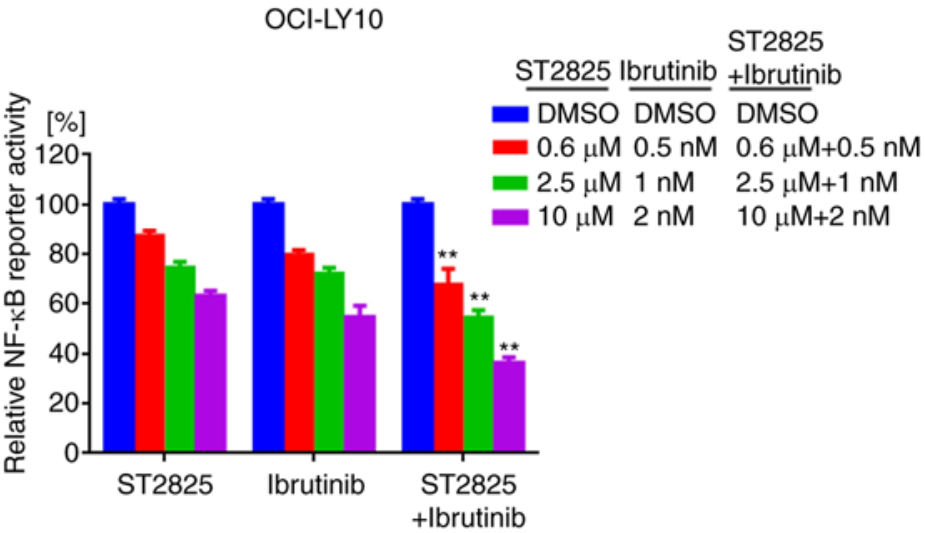

Figure 5. Synergistic effects of BTK inhibitor and myddosome assembly inhibitor on ABC DLBCL cells. (A, B) OCI-LY10 cells were treated for $72 \mathrm{~h}$ with ibrutinib, ST2825 or both, at the indicated doses, followed by a WST-1 assay. Inhibition at varying dosimetry values for the inhibitor of BTK (ibrutinib) and MYD88 (ST2825) in OCI-LY10 cells is depicted with (A) heat maps and (B) line graphs. (C) Synergism was evaluated via CI analysis, and the CI values of OCI-LY10 cells at varying dosimetry values for ibrutinib and ST2825 are demonstrated via heat maps. (D) Relative NF- $\mathrm{kB}$ luciferase activity was measured, following treatment of the OCI-LY10 cells for $12 \mathrm{~h}$ with the indicated concentrations of ibrutinib, ST2825 or both. Statistical analysis by one-way ANOVA and Tukey's post hoc test. Data are presented as the mean \pm standard error of the mean from three independent experiments. ${ }^{* *} \mathrm{P}<0.01$. BTK, Bruton's tyrosine kinase; ABC, activated B cell; DLBCA, diffuse large B-cell lymphoma; MYD88, myeloid differentiation primary response gene 88; CI, combination index; $\mathrm{NF}-\mathrm{\kappa B}$, nuclear factor kappa-light-chain-enhancer of activated B cells.

interacted with BTK in L265P ABC DLBCL cell lines, and that the binding between MYD88 and BTK was abrogated by ST2825. Furthermore, the present study demonstrated that the use of ST2825 inhibited BTK activity in MYD88 L265P-expressing ABC DLBCL cell lines. Collectively, the present study demonstrated that when bound to BTK, MYD88 L265P could influence the activity of the former. Given the association between MYD88 and BTK, and their critical oncogenic roles in L265P-expressing ABC DLBCL cells, the present study investigated the effects of the dual inhibition of MYD88 and BTK. The data revealed that the combined use of ST2825 and ibrutinib resulted in synergistic killing effects, which were associated with enhanced inhibition of NF- $\mathrm{kB}$ activity.

Based on the pathways regulated by MYD88 L265P activity, there are several therapeutic strategies that have been designed to halt this specific oncogenic process. The targets of these therapies include BTK, IRAK1/4, JAK and myddosome assembly. The BTK inhibitor ibrutinib, the only U.S. Food and Drug Administration approved drug capable of influencing the L265P driven pathway (potentially by abrogating the MYD88-BTK complex), inhibits the survival of L265P-expressing cell lines, which is consistent with the observations of the present study. A phase $1 / 2$ clinical trial demonstrated that ibrutinib produced total responses in $37 \%$ of 38 patients with ABC DLBCL (17). The patients with concurrent MYD88 and BCR component mutations appeared to be more sensitive to ibrutinib, while those with MYD88 mutations independent of chronically-active BCR signaling exhibited resistance to ibrutinib. This indicates that novel drugs that are more specific to MYD88 signaling require further investigation. A number of IRAK inhibitors have demonstrated convincing abilities to inhibit the growth of L265P-expressing cell lines in pre-clinical models (39-41). However, MYD88 dimerization may present a more favorable target considering its proximity to the origin of hyperactivity, particularly as IRAKs are not involved in all MyD88-dependent signaling. Mini-peptides that have been designed to compete with MYD88 TIR domain interactions disrupted myddosome signaling and blocked WM cell proliferation $(42,43)$. Notably, ST2825 is a synthetic compound, created to mimic a portion in the BB-loop of the MYD88 TIR domain, which can inhibit MYD88 dimerization (14). In the present study, the use of ST2825 disrupted myddosome assembly and contributed to growth inhibition, as well as attenuating NF- $\mathrm{kB}$ activity in L265P ABC DLBCL cell lines.

The MYD88 L265P mutation frequently occurs alongside other genetic events in ABC-DLBCLs, such as CD79B mutations (44-46), loss of the tumor suppressor TNFAIP3 or the overexpression of BCL-2 $(30,34)$. It has also been revealed that to induce lymphoma formation, MYD88 L265P may need to occur in addition to other genetic alterations, while 
A

\begin{tabular}{|c|c|c|c|c|c|c|}
\hline & 0 & 0.1 & 0.4 & 1.3 & 4 & 12 \\
\hline 0 & 0 & 10.6 & 16.2 & 33.1 & 45.6 & 62.3 \\
\hline 0.12 & 19.1 & 16.8 & 20.9 & 35.1 & 42.7 & 63.8 \\
\hline 0.25 & 25.9 & 24.9 & 30.2 & 39.3 & 47.1 & 60.9 \\
\hline 0.5 & 37.7 & 43.5 & 42.7 & 45.8 & 60.1 & 68.4 \\
\hline 1 & 45.5 & 42.9 & 46.9 & 59.3 & 68.2 & 77 \\
\hline 2 & 61.8 & 65.5 & 69.4 & 68.8 & 72.6 & 79.2 \\
\hline
\end{tabular}

C

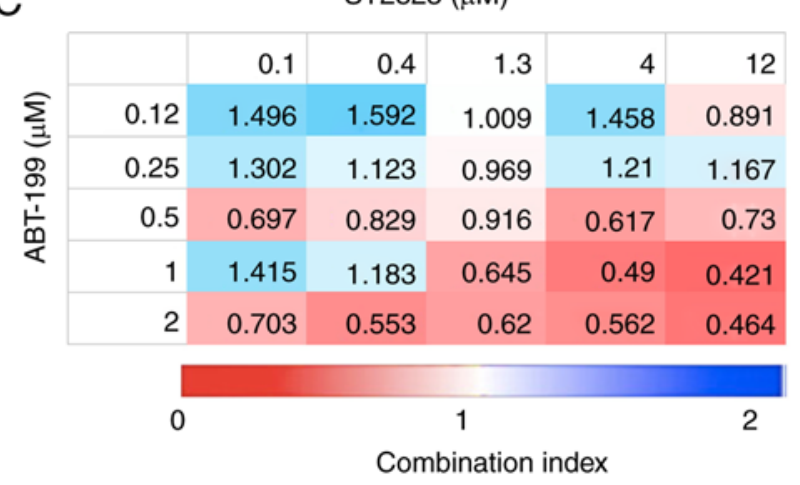

B
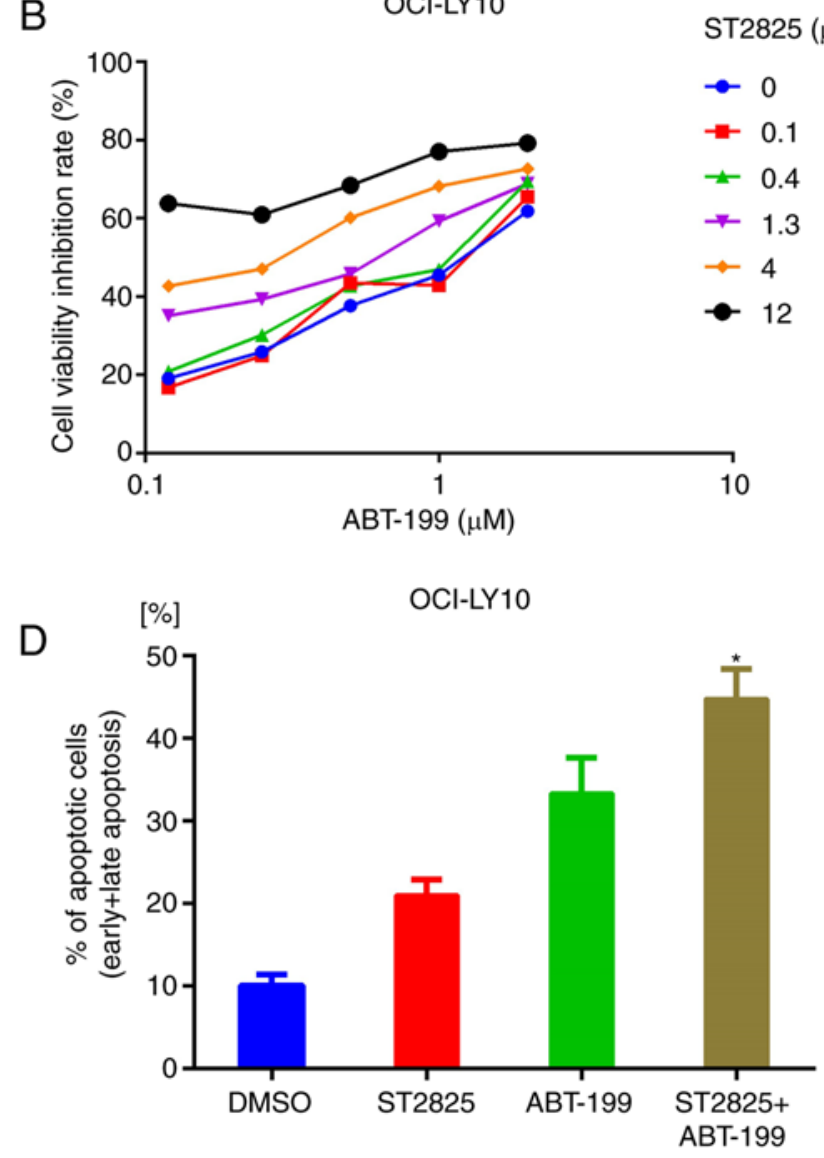

Figure 6. Synergistic effect of BCL-2 inhibitor and myddosome assembly inhibitor on ABC DLBCL cells. (A, B) OCI-LY10 cells were treated for $72 \mathrm{~h}$ with ABT-199, ST2825 or both, at the indicated doses, followed by a WST-1 assay. Inhibition at varying dosimetries for the inhibitor of BCL-2 (ABT-199) and MYD88 (ST2825) in OCI-LY10 cells is depicted with (A) heat maps and (B) line graphs. (C) Synergism was evaluated via CI analysis, and the CI values of OCI-LY10 cells at varying dosimetry values for ABT-199 and ST2825 are demonstrated via heat maps. (D) Apoptotic cell population (annexin V-positive) of OCI-LY10 cells analyzed by flow cytometry, following treatment for $48 \mathrm{~h}$ with the vehicle, ST2825 $(10 \mu \mathrm{M})$, ABT-199 $(1 \mu \mathrm{M})$ or combination treatment. Statistical analysis by one-way ANOVA with Tukey's post hoc test. Data are presented as the mean \pm standard deviation "P<0.05. BCL-2, B-cell lymphoma-2; ABC, activated B cell; DLBCA, diffuse large B-cell lymphoma; MYD88, myeloid differentiation primary response gene 88; CI, combination index.

MYD88 mutations alone are potentially not sufficient. It has been reported that MYD88 L265P and CD79B mutations cooperate to block peripheral deletions and promote spontaneous plasmablast differentiation in B cells (46). In addition, TNFAIP3 loss enhances NF- $\kappa B$ signaling driven by MYD88 L265P, and contributes to ibrutinib resistance in lymphoma cell lines. Furthermore, MYD88 mutations cooperate with BCL-2 overexpression to promote self-reactive $\mathrm{B}$ cell accumulation and lymphomagenesis in vivo $(30,34)$. These findings provide a framework for the rational design of combination therapy with dual inhibitors, targeting multiple signaling pathways. The present study demonstrated that the dual inhibition of MYD88 oligomerization (ST2825) and BTK activity (ibrutinib) results in synergistic cell death by decreasing NF- $\mathrm{\kappa B}$ activity. It was also observed that combined treatment targeting both the myddosome (ST2825) and BCL-2 (ABT-199) lead to synergistic toxicity and increased apoptosis in ABC DLBCL cell lines.

To the best of our knowledge, the present study is the first to report that myddosome assembly is disrupted by the synthetic small-molecule compound ST2825 in MYD88 L265P ABC DLBCL cells, resulting in proliferation inhibition, increased apoptosis and decreased NF- $\mathrm{kB}$ activity. The interplay between the MYD88 mutant and BTK further confirms that oncogenic
MYD88 L265P cooperates with BCR signaling to promote tumor cell survival. It was subsequently revealed that combined ST2825, either with the BTK inhibitor ibrutinib, or the BCL-2 inhibitor ABT-199, resulted in synergistic cell death in ABC DLBCL cells. Therefore, targeting myddosome assembly may be a promising therapeutic strategy for MYD88-mutated ABC DLBCL. Future studies may focus on developing more ST2825-like synthetic peptidomimetic compounds with improved efficacy and safety.

\section{Acknowledgements}

The authors would like to thank Roman Jerala and Mateja M. Keber for supplying the plasmids and for their helpful discussion.

\section{Funding}

The present work was supported by the Chongqing Research Program of Basic Research and Frontier Technology (grant no. cstc2017jcyjA0632), Chongqing Health and Family Planning Commission Grant (grant no.zy201402109) to XW, and the Science and Technology Research Program of Chongqing 
Municipal Education Commission (grant no. KJ1600225) to Jing Hu.

\section{Availability of data and materials}

All data generated or analyzed during the present study are included in this published article (and its Supplementary files).

\section{Authors' contributions}

XW designed the research studies, performed the experiments, analyzed the data and wrote the manuscript. YT and NSH performed the experiments. JH and FZZ analyzed data and critically revised the manuscript. ZLH and MG collected and analyzed the data. WLF supervised the experimental work and critically revised the manuscript. All authors read and approved the final manuscript.

\section{Ethics approval and consent to participate}

Not applicable.

\section{Patient consent for publication}

Not applicable.

\section{Competing interests}

The authors declare that they have no competing interests.

\section{References}

1. Teras LR, DeSantis CE, Cerhan JR, Morton LM, Jemal A and Flowers CR: 2016 US lymphoid malignancy statistics by World Health Organization subtypes. CA Cancer J Clin 66: 443-459, 2016.

2. Bray F, Ferlay J, Soerjomataram I, Siegel RL, Torre LA and Jemal A: Global cancer statistics 2018: GLOBOCAN estimates of incidence and mortality worldwide for 36 cancers in 185 countries. CA Cancer J Clin 68: 394-424, 2018.

3. Alizadeh AA, Eisen MB, Davis RE, Ma C, Lossos IS, Rosenwald A, Boldrick JC, Sabet H, Tran T, Yu X, et al: Distinct types of diffuse large B-cell lymphoma identified by gene expression profiling. Nature 403: 503-511, 2000.

4. Pfreundschuh M, Kuhnt E, Trümper L, Osterborg A, Trneny M, Shepherd L, Gill DS, Walewski J, Pettengell R, Jaeger U, et al: CHOP-like chemotherapy with or without rituximab in young patients with good-prognosis diffuse large-B-cell lymphoma: 6-year results of an open-label randomised study of the MabThera International Trial (MInT) Group. Lancet Oncol 12: 1013-1022, 2011.

5. Rawlings DJ, Schwartz MA, Jackson SW and Meyer-Bahlburg A: Integration of $\mathrm{B}$ cell responses through Toll-like receptors and antigen receptors. Nat Rev Immunol 12: 282-294, 2012.

6. Davis RE, Ngo VN, Lenz G, Tolar P, Young RM, Romesser PB Kohlhammer H, Lamy L, Zhao H, Yang Y, et al: Chronic active B-cell-receptor signalling in diffuse large B-cell lymphoma. Nature 463: 88-92, 2010.

7. Lenz G, Davis RE, Ngo VN, Lam L, George TC, Wright GW, Dave SS, Zhao H, Xu W, Rosenwald A, et al: Oncogenic CARD11 mutations in human diffuse large B cell lymphoma. Science 319: $1676-1679,2008$.

8. Ngo VN, Young RM, Schmitz R, Jhavar S, Xiao W, Lim KH, Kohlhammer H, Xu W, Yang Y, Zhao H, et al: Oncogenically active MYD88 mutations in human lymphoma. Nature 470: 115-119, 2011.

9. Medzhitov R, Preston-Hurlburt P and Janeway CA Jr: A human homologue of the Drosophila Toll protein signals activation of adaptive immunity. Nature 388: 394-397, 1997.
10. Ntoufa S, Vilia MG, Stamatopoulos K, Ghia P and Muzio M: Toll-like receptors signaling: A complex network for NF- $\kappa$ B activation in B-cell lymphoid malignancies. Semin Cancer Biol 39: $15-25,2016$

11. Lin SC, Lo YC and Wu H: Helical assembly in the MyD88IRAK4-IRAK2 complex in TLR/IL-1R signalling. Nature 465: 885-890, 2010.

12. Yu X, Li W, Deng Q, Li L, His ED, Young KH, Zhang M and Li Y: MYD88 L265P mutation in lymphoid malignancies. Cancer Res 78: 2457-2462, 2018.

13. Avbelj M, Wolz OO, Fekonja O, Benčina M, Repič M, Mavri J, Krüger J, Schärfe C, Delmiro Garcia M, Panter G, et al: Activation of lymphoma-associated MyD88 mutations via allostery-induced TIR-domain oligomerization. Blood 124: 3896-3904, 2014.

14. Loiarro M, Capolunghi F, Fantò N, Gallo G, Campo S, Arseni B, Carsetti R, Carminati P, De Santis R, Ruggiero V and Sette C: Pivotal advance: Inhibition of MyD88 dimerization and recruitment of IRAK1 and IRAK4 by a novel peptidomimetic compound. J Leukoc Biol 82: 801-810, 2007.

15. Li H, Huang Z, Gao M, Huang N, Luo Z, Shen H, Wang X, Wang T, Hu J and Feng W: Inhibition of YAP suppresses CML cell proliferation and enhances efficacy of imatinib in vitro and in vivo. J Exp Clin Cancer Res 35: 134, 2016.

16. Chou TC: Drug combination studies and their synergy quantification using the Chou-Talalay method. Cancer Res 70: 440-446, 2010.

17. Wilson WH, Young RM, Schmitz R, Yang Y, Pittaluga S, Wright G, Lih CJ, Williams PM, Shaffer AL, Gerecitano J, et al: Targeting B cell receptor signaling with ibrutinib in diffuse large B cell lymphoma. Nat Med 21: 922-926, 2015.

18. Jefferies CA, Doyle S, Brunner C, Dunne A, Brint E, Wietek C, Walch E, Wirth T and O'Neill LA: Bruton's tyrosine kinase is a Toll/interleukin-1 receptor domain-binding protein that participates in nuclear factor kappaB activation by Toll-like receptor 4 . J Biol Chem 278: 26258-26264, 2003.

19. Liu X, Zhan Z, Li D, Xu L, Ma F, Zhang P, Yao H and Cao X: Intracellular MHC class II molecules promote TLR-triggered innate immune responses by maintaining activation of the kinase Btk. Nat Immunol 12: 416-424, 2011.

20. Phelan JD, Young RM, Webster DE, Roulland S, Wright GW, Kasbekar M, Shaffer AL III, Ceribelli M, Wang JQ, Schmitz R, et al: A multiprotein supercomplex controlling oncogenic signalling in lymphoma. Nature 560: 387-391, 2018.

21. Cory S and Adams JM: The Bcl2 family: Regulators of the cellular life-or-death switch. Nat Rev Cancer 2: 647-656, 2002.

22. Lenz G, Wright GW, Emre NC, Kohlhammer H, Dave SS Davis RE, Carty S, Lam LT, Shaffer AL, Xiao W, et al: Molecular subtypes of diffuse large B-cell lymphoma arise by distinct genetic pathways. Proc Natl Acad Sci USA 105: 13520-13525, 2008.

23. Iqbal J,Neppalli VT, WrightG,Dave BJ,Horsman DE, Rosenwald A, Lynch J, Hans CP, Weisenburger DD, Greiner TC, et al: BCL2 expression is a prognostic marker for the activated B-cell-like type of diffuse large B-cell lymphoma. J Clin Oncol 24: 961-968, 2006.

24. Davids MS: Targeting BCL-2 in B-cell lymphomas. Blood 130: 1081-1088, 2017.

25. Chapuy B, Stewart C, Dunford AJ, Kim J, Kamburov A, Redd RA, Lawrence MS, Roemer MGM, Li AJ, Ziepert M, et al: Molecular subtypes of diffuse large B cell lymphoma are associated with distinct pathogenic mechanisms and outcomes. Nat Med 24: 679-690, 2018.

26. Schmitz R, Wright GW, Huang DW, Johnson CA, Phelan JD, Wang JQ, Roulland S, Kasbekar M, Young RM, Shaffer AL, et al: Genetics and pathogenesis of diffuse large B-cell lymphoma. N Engl J Med 378: 1396-1407, 2018.

27. Fernández-Rodríguez C, Bellosillo B, García-García M, Sánchez-González B, Gimeno E, Vela MC, Serrano S, Besses C and Salar A: MYD88 (L265P) mutation is an independent prognostic factor for outcome in patients with diffuse large B-cell lymphoma. Leukemia 28: 2104-2106, 2014.

28. Weber ANR, Cardona Gloria Y, Çınar Ö, Reinhardt HC, Pezzutto A and Wolz OO: Oncogenic MYD88 mutations in lymphoma: Novel insights and therapeutic possibilities. Cancer Immunol Immunother 67: 1797-1807, 2018.

29. Janz S: Mouse model of MYD88L265P-dependent DLBCL. Blood 127: 2660-2661, 2016.

30. Knittel G, Liedgens P, Korovkina D, Seeger JM, Al-Baldawi Y, Al-Maarri M, Fritz C, Vlantis K, Bezhanova S, Scheel AH, et al: B-cell-specific conditional expression of Myd88p.L252P leads to the development of diffuse large B-cell lymphoma in mice. Blood 127: 2732-2741, 2016. 
31. Hardiman G, Rock FL, Balasubramanian S, Kastelein RA and Bazan JF: Molecular characterization and modular analysis of human MyD88. Oncogene 13: 2467-2475, 1996.

32. Fekonja O, Benčina M and Jerala R: Toll/interleukin-1 receptor domain dimers as the platform for activation and enhanced inhibition of Toll-like receptor signaling. J Biol Chem 287: 30993-31002, 2012.

33. Jing X, Tian Z, Gao P, Xiao H, Qi X, Yu Y, Ding X, Yang L

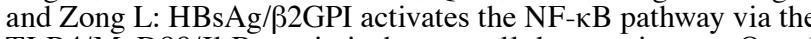
TLR4/MyD88/IkB $\alpha$ axis in hepatocellular carcinoma. Oncol Rep 40: 1035-1045, 2018.

34. Wang JQ, Jeelall YS, Beutler B, Horikawa $\mathrm{K}$ and Goodnow CC: Consequences of the recurrent MYD88(L265P) somatic mutation for B cell tolerance. J Exp Med 211: 413-426, 2014.

35. Vyncke L, Bovijn C, Pauwels E, Van Acker T, Ruyssinck E, Burg E, Tavernier $J$ and Peelman F: Reconstructing the TIR side of the myddosome: A paradigm for TIR-TIR interactions. Structure 24: 437-447, 2016.

36. Ohnishi H, Tochio H, Kato Z, Orii KE, Li A, Kimura T, Hiroaki H, Kondo N and Shirakawa M: Structural basis for the multiple interactions of the MyD88 TIR domain in TLR4 signaling. Proc Natl Acad Sci USA 106: 10260-10265, 2009.

37. Pasqualucci $\mathrm{L}$ and Zhang B: Genetic drivers of NF- $\kappa \mathrm{B}$ deregulation in diffuse large B-cell lymphoma. Semin Cancer Biol 39: 26-31, 2016.

38. Yang G, Zhou Y, Liu X, Xu L, Cao Y, Manning RJ, Patterson CJ, Buhrlage SJ, Gray N, Tai YT, et al: A mutation in MYD88 (L265P) supports the survival of lymphoplasmacytic cells by activation of Bruton tyrosine kinase in Waldenström macroglobulinemia. Blood 122: 1222-1232, 2013

39. Kelly PN, Romero DL, Yang Y, Shaffer AL III, Chaudhary D Robinson S, Miao W, Rui L, Westlin WF, Kapeller R and Staudt LM: Selective interleukin-1 receptor-associated kinase 4 inhibitors for the treatment of autoimmune disorders and lymphoid malignancy. J Exp Med 212: 2189-2201, 2015.
40. Markovtsov VV, Lamagna C, Chan M, Yi S, Young C, Frances R, Siu S, Braselmann S, Li H, Singh R, et al: Potential role for R191, potent and selective IRAK4 kinase inhibitor, in treatment of hematologic malignancies. AACR Abstract, 2016.

41. Ni H, Shirazi F, Baladandayuthapani V, Lin H, Kuiatse I, Wang H, Jones RJ, Berkova Z, Hitoshi Y, Ansell SM, et al: Targeting myddosome signaling in Waldenström's macroglobulinemia with the interleukin-1 receptor-associated kinase 1/4 inhibitor R191. Clin Cancer Res 24: 6408-6420, 2018.

42. Treon SP, Xu L, Yang G, Zhou Y, Liu X, Cao Y, Sheehy P, Manning RJ, Patterson CJ, Tripsas C, et al: MYD88 L265P somatic mutation in Waldenström's macroglobulinemia. N Engl J Med 367: 826-833, 2012.

43. Liu X, Hunter ZR, Xu L, Chen J, Chen JG, Tsakmaklis N, Patterson CJ, Castillo JJ, Buhrlage S, Gray N, et al: Targeting myddosome assembly in Waldenström macroglobulinaemia. $\mathrm{Br}$ J Haematol 177: 808-813, 2017.

44. Kim Y, Ju H, Kim DH, Yoo HY, Kim SJ, Kim WS and Ko YH: CD79B and MYD88 mutations in diffuse large B-cell lymphoma. Hum Pathol 45: 556-564, 2014.

45. Yamada S, Ishida Y, Matsuno A and Yamazaki K: Primary diffuse large B-cell lymphomas of central nervous system exhibit remarkably high prevalence of oncogenic MYD88 and CD79B mutations. Leuk Lymphoma 56: 2141-2145, 2015.

46. Wang JQ, Jeelall YS, Humburg P, Batchelor EL, Kaya SM, Yoo HM, Goodnow CC and Horikawa K: Synergistic cooperation and crosstalk between MYD88 ${ }^{\mathrm{L} 265 \mathrm{P}}$ and mutations that dysregulate CD79B and surface IgM. J Exp Med 214: 2759-2776, 2017.

This work is licensed under a Creative Commons Attribution-NonCommercial-NoDerivatives 4.0 International (CC BY-NC-ND 4.0) License. 